\title{
Proteome Profile Changes During Poly- hydroxybutyrate Intracellular Mobilization in Gram Positive Bacillus cereus tsu1
}

HUI LI

Tennessee State University

Joshua O'Hair

Tennessee State University

Santosh Thapa

Tennessee State University

Sarabjit Bhatti

Tennessee State University

Suping Zhou ( $\nabla$ zsuping@tnstate.edu )

Yong Yang

USDA-ARS

Tara Fish

USDA-ARS

Theodore W. Thannhauser

USDA-ARS

\section{Research article}

Keywords: Bacillus cereus, Quantitative proteomics, Poly-hydroxybutyrate, Sporulation, Fermentative growth

Posted Date: February 19th, 2020

DOI: https://doi.org/10.21203/rs.2.15633/v2

License: (c) (i) This work is licensed under a Creative Commons Attribution 4.0 International License.

Read Full License

Version of Record: A version of this preprint was published at BMC Microbiology on May 19th, 2020. See the published version at https://doi.org/10.1186/s12866-020-01815-6. 


\section{Abstract}

Background Bacillus cereus is a bacterial species which grows efficiently on a wide range of carbon sources and accumulates biopolymer poly-hydroxybutyrate (PHB) up to $80 \%$ cell dry weight. PHB is an aliphatic polymer produced and stored intracellularly as a reservoir of carbon and energy, its mobilization is a key biological process for sporulation in Bacillus spp. Previously, a B. cereus tsu1 was isolated and cultured on rapeseed cake substrate (RCS), with maximum of PHB accumulation reached within $12 \mathrm{~h}$, and depleted after $48 \mathrm{~h}$; fore-spore and spore structure were observed after $24 \mathrm{~h}$ culture. Results Quantitative proteomic analysis of B. cereus tsu1 identified 2,952 quantifiable proteins, and 244 significantly changed proteins (SCPs) in the $24 \mathrm{~h}-12 \mathrm{~h}$ pair of samples, $325 \mathrm{SCPs}$ in the $48 \mathrm{~h}-12 \mathrm{~h}$ pair of samples. Based on gene ontology classification analysis, biological processes enriched only in the 24h:12h SCPs include purine nucleotide metabolism, protein folding, metal ion homeostasis, response to stress, carboxylic acid catabolism, and cellular amino acid catabolism. The 48h:12h SCPs were enriched into processes including carbohydrate metabolism, protein metabolism, oxidative phosphorylation, and formation of translation ternary structure. A key enzyme for PHB metabolism, poly(R)-hydroxyalkanoic acid synthase (PhaC, KGT44865) accumulated significantly higher in 12h-culture. Sporulation related proteins SigF and SpoEll were significantly higher in $24 \mathrm{~h}$-samples. Enzymes for nitrate respiration and fermentation accumulated at a higher level in 48h-culture. Conclusions Changes in proteome of B. cereus tsu1 during PHB intracellular mobilization were characterized in this study. The key enzyme PhaC for PHB synthesis increased significantly after $12 \mathrm{~h}$-culture which supports the highest PHB accumulation at this time point. The protein abundance level of SpollE and SigF were increased which is correlated with sporulation in 24h-culture. Enzymes for nitrate respiration and fermentation were significantly induced in 48h-culture which indicates the depletion of oxygen at this stage and carbon flow towards fermentative growth. Results from this study provide insights into proteome profile changes during PHB accumulation and reuse, which can be applied to achieve a higher PHB yield and to improve bacterial growth performance and stress resistance.

\section{Background}

Bacillus cereus is a gram-positive, facultative anaerobic bacterium that is widely found in soil and other environments. This species of bacteria can grow efficiently by assimilating a wide range of carbon sources including glucose, sucrose, glycerol, oil fat, etc. [1]. It was reported that $B$. cereus can produce intracellular poly-hydroxyalkanoates (PHAs), which can account for up to $80 \%$ cell dry weight [2]. PHAs are a class of aliphatic polyesters produced by a large number of bacteria as a reservoir of carbon and energy [3]. Poly-3-hydroxybutyrate (PHB) is the first and most well characterized member in the PHA family discovered in 1925, since then more than 100 polymer structures have been identified in this family with different physical properties [4]. The PHA-derived plastics is biodegradable, biocompatible, water insoluble, oxygen permeable and high-temperature resistant. These advantageous characteristics have made them a promising replacement for petroleum-based plastics [5]; even so, the high production cost remains as the major limitation in using PHAs bioplastics on commercial scales [6]. 
PHA polymers are accumulated and stored as intracellular granules under excess carbon supply, and then mobilized during carbon-limited conditions. Bacterial PHAs synthesis can utilize substrates derived from metabolic pathways such as acetyl-CoA (from glycolysis), enoyl-CoA (from fatty acid $\beta$-oxidation) and (R)-3-hydroxy-acyl-ACP (from fatty acid de novo synthesis) [7, 8]. The most prevalent PHB biosynthesis pathway starts with acetyl-CoA and goes through condensation, reduction and polymerization catalyzed by acetyl-CoA acetyltransferase (PhaA), acetoacetyl-CoA reductase (PhaB), PHA synthase (PhaC) respectively for the final PHB production. In another common pathway, enoyl-CoA from fatty acid $\beta$ oxidation is first oxidized to (R)-3-hydroxyacyl-CoA by (R)-specific enoyl-CoA hydratase (PhaJ) before polymerized into PHB polymer by PhaC [9]. The genes encoding for PHB biosynthesis enzymes are often co-localized and organized in an operon. For PHB degradation, the polymer is first depolymerized into its monomer by PHB depolymerase (PhaZ). The elucidation of the PHB reuse mechanism is still in progress. Previous research was able to detect (S)-3-hydroxybutyryl CoA, crotonyl-CoA and acetyl-CoA as PHB degradation intermediates, which links PHB mobilization with other primary and secondary metabolic pathways like glycolysis, $\beta$-oxidation, and TCA cycle [10].

In Bacillus spp., another key feature is the sporulation process which produces dormant endospores under nutritional stresses [11]. Even though, a variety of self-rescue mechanisms are triggered by starvation, such as the activation of chemotaxis proteins, secretion of hydrolytic enzymes to recycle extracellular energy, sporulation is considered to be the ultimate response [12]. In response to the nutrient depletion as a signal for endospore formation, PHB degradation occurs. In culture, PHB reaches the highest level of accumulation before the formation of fore-spore structure and starts degrading during endospore maturation [13]. More evidences of PHB being mobilized for sporulation came from a study showing that the deficiency in PHB production was associated with reduced spore formation, and the supplementation of exogenous fatty acids was able to recover this sporulation process [14].

When encountering anoxic conditions, many Bacillus spp. are capable of using nitrate as electron acceptor, where the various substrate dehydrogenases transfer electrons to the acceptor reductases (nitrate and nitrite reductases). In these Bacillus spp., nitrate reduction is always coupled with the fermentative growth, during which ATP is produced by the conversion of pyruvate and acetyl-CoA to a range of fermentative end-products (lactate, acetate, ethanol) [15, 16, 17]. Dissolved oxygen (DO) level is an important factor in PHB production using Bacillus spp. A higher PHB yield can be achieved by reducing DO from $40 \%$ to $20 \%$, whereas severe PHB degradation was observed when DO further dropped down to $5-10 \%$ [18]. Consequently, DO level in culture can determine either the shift of acetyl-CoA towards PHB synthesis or the degradation of stored PHB to feed into other metabolic pathways.

Previously, our lab reported isolation of $B$. cereus tsu1, the genome was predicted to have 5,763 proteins (NCBI accession no. JPYN01; https://www.ncbi.nlm.nih.gov/Traces/wgs/JPYN01? display=proteins\&page=1) [19]. In this study, B. cereus tsu1 was cultured on rapeseed cake substrate (RCS) without additional supplements as described before [20]. When examined under microscope, the maximum of PHB accumulation was reached within $12 \mathrm{~h}$ (before stationary phase) and it was nearly depleted in $48 \mathrm{~h}$ (when mature endospores were released). A quantitative proteomic analysis during this 
process was performed to identify the proteomic profile changes of $B$. cereus tsu1 for a better understanding of PHB mobilization mechanisms and to discover strategies in improving bacterial growth performance to achieve a higher PHB yield.

\section{Results}

Growth Phases and PHB Intracellular Mobilization of B. cereus tsu1. Bacillus cereus tsu1 was cultured using RCS medium and cells were stained with Sudan black to observe PHB accumulation status (Fig. 1). In 6h-culture, PHB granules were observable but smaller in size. In 9h-culture, the granules aggregated and formed clusters, and reached the highest accumulation before $12 \mathrm{~h}$. Bacterial cells were collected at $12 \mathrm{~h}, 24 \mathrm{~h}, 48 \mathrm{~h}$ and stored at $-20^{\circ} \mathrm{C}$ for protein extraction. The reasons for selecting these three time points were 1) bacterial cells in 12h-culture were loaded with PHB when examined using the Sudan black staining method; 2 ) in 24h-culture, most cells were still filled with PHB, but some cells were sporulating with fore-spore, and spore structure visible under the microscope; 3 ) significant degradation of PHB was observed in 48h-culture, and even though some mature endospores were released, most cells were still in vegetative state. In this study, quantitative proteomics analysis was performed by comparing difference in protein abundance level between $24 \mathrm{~h}$ - and $12 \mathrm{~h}$-samples to determine enzymes related with PHB biosynthesis, cellular stress and sporulation; and by comparing between $48 \mathrm{~h}$ - and $12 \mathrm{~h}$-samples for detection of enzymes associated with PHB degradation and other related metabolic pathways.

Quantitative Proteomic Profile and Identification of Significantly Changed Proteins. SDS phenol based method was used for proteins extraction from bacterial cells cultured in RCS medium for 12, 24 and $48 \mathrm{~h}$. Three biological replicates were included for each time point. After trypsin digestion, samples were labeled with nine tags from a 10-plex tandem mass tags (TMT) kit. The nano-LC-MS/MS identified 3,215 proteins, from where 2,952 proteins were quantified each with two or more unique peptides. The $\log _{2}{ }^{-}$ transformed abundance of all constituent peptides were subjected to a t-test followed by false discovery rate (FDR) correction analysis. A protein with $\geq 1.5$ standard deviations from normal distribution curve of each quantified protein and a FDR adjusted $p$-value $\leq 0.05$ was regarded as being significantly changed proteins (SCPs) for each pair of sampling time-points $(24 \mathrm{~h} / 12 \mathrm{~h}$, or $48 \mathrm{~h} / 12 \mathrm{~h})$. Protein fold changes were obtained from anti-log conversion of $\log _{2}$ ratios. When comparing $24 \mathrm{~h}$ - and $12 \mathrm{~h}$-samples, there were 244 significantly changed proteins (SCPs) which passed the thresholds [FDR $<0.05$, and fold changes $(24 \mathrm{~h} / 12 \mathrm{~h})<0.76$ or $>1.31$ ], including 56 up-regulated and 188 down-regulated proteins; in $48 \mathrm{~h}-12 \mathrm{~h}$ pair of samples, 325 proteins passed the thresholds [FDR $<0.05$, and fold changes $(48 \mathrm{~h} / 12 \mathrm{~h})<0.67$ or $>1.50$ ], with 145 proteins up-regulated and 180 down-regulated proteins (Fig. 2A, Additional file 1: Table S1-1). Results of t-test and FDR analyses using SAS were listed in the Additional file 2.

The identified SCPs were analyzed for functional classification using the PANTHER classification system (v.14.1). The biological processes enriched only in 24h:12h up-regulated SCPs include purine nucleotide metabolism, protein folding, metal ion homeostasis, response to stress; the $24 \mathrm{~h}$ down-regulated SCPs are classified into processes of carboxylic acid catabolism, cellular amino acid catabolism, peptidoglycan biosynthetic process, RNA process. The 48h:12h SCPs were enriched into biological processes including 
carbohydrate metabolism, protein metabolism, oxidative phosphorylation, formation of translation ternary structure (Fig. 2B).

Enzymes for PHB Biosynthesis and Intracellular Degradation. The maximum of PHB accumulation in $B$. cereus tsu1 was observed within $12 \mathrm{~h}$. According to a previous study [20], the $B$. cereus tsu1 was annotated with genes in three different pathways for PHB polymerization (Fig. 3). The primary pathway starts with acetyl-CoA, using enzymes encoded by a pha locus which consists of phaR-phaB-phaCoperon and phaP-phaQ-phaJ operon in the opposite direction. In the second pathway, intermediates of fatty acid $\beta$-oxidation could flow into the PHB synthesis pathway catalyzed by acyl-CoA dehydrogenase (AcdA_1 and AcdA_2) and 3-hydroxybutyryl-CoA dehydratase/ enoyl-CoA hydratase (PhaJ). PhaJ is the key enzyme to provide (R)-3HB-CoA monomer for PHB synthesis. The third pathway involves using succinylCoA from TCA cycle to produce PHB [21]. Succinyl-CoA is first converted to SSA by SSA dehydrogenase (GabD, KGT45610) followed by reduction of SSA into GABA by 4-hydroxybutyrate dehydrogenase (GabT, KGT45608). GABA is activated to R-hydroxybutyryl-CoA by a succinyl-CoA-coenzyme A transferase enzyme (ScoT). The R-hydroxybutyryl-CoA could then be polymerized into PHB with PhaC [7]. STRING database (version 10.5) of $B$. cereus was used for protein-protein interaction network construction. In the 48h-sample, PHB was observed to have undergone significant degradation. For PHB degradation, the enzyme 3-oxoadipate enol-lactonase which previously confirmed with PHB intracellular degradation activity in B. thuringiensis ATCC35646 [22] was annotated on the $B$. cereus tsu1 genome, and this protein was quantified in this study.

Enzymes for PHB biosynthesis and intracellular degradation and their abundance were compared among the three time-point samples (Fig. 3). Poly(R)-hydroxyalkanoic acid synthase (PhaC, KGT44865) had the highest abundance level at early stage of bacterial growth, while the synthase subunit PhaR (KGT44863) displayed an opposite change. PhaR protein was reported as a global regulation factor, with an impact on PHB biosynthesis [23, 24]. Both 3-oxoacyl-ACP synthase (PhaB, KGT44864) and phasin protein (PhaP, KGT44861) accumulated to the highest abundance level at 48h. PhaQ (KGT44862), previously identified as a new class of PHB synthesis transcription regulator, was not identified in the proteome analysis. Both AcdA_2 (KGT41138) and PhaJ (KGT44860) involved in PHB biosynthesis using fatty acid $\beta$-oxidation intermediate had a higher abundance level at $12 \mathrm{~h}$ [25]. Additionally, a majority of enzymes converting glutamate and GABA to PHB were observed with a higher abundance level at $12 \mathrm{~h}$. ScoT (KGT44257) is an enzyme associated with both PHB synthesis and consumption; its abundance reached the highest level in 48h-sample. Despite of significant PHB degradation observed at $48 \mathrm{~h}$, the abundance of 3oxoadipate enol-lactonase (KGT42842) for PHB depolymerization was at highest level at $12 \mathrm{~h}$ and slightly reduced over time.

PHB Mobilization and Other Metabolic Pathways. In Bacillus spp., PHB formation and mobilization are important metabolic processes interacting with other major pathways. As shown in Fig. 4A, PHB biosynthesis starts with acetyl-CoA, which is a molecule that participates in several essential biochemical reactions including glycolysis, lipid and protein metabolism, TCA. PHB mobilization and recycling provide carbon and energy resource for other metabolic pathways such as pyruvate fermentation and butanoate 
metabolism [26]. Therefore, bacteria which experienced incomplete PHB mobilization were observed with deficient sporulation and lower stress tolerance.

In this study, most enzymes in Embden-Meyerhof-Parnas (EMP) pathway, pentose phosphate (PP) pathway, and TCA cycle did not show significant changes among the three time points (Additional file 1: Table S1-2). In EMP, glucose-6-phosphate isomerase (KGT41362) was significantly down-regulated at 0.7 and 0.58 fold in 24h- and 48h-samples. In PP, 6-phosphogluconate dehydrogenase (KGT42918) was down-regulated ( 0.66 fold) at $48 \mathrm{~h}$. In glyoxylate shunt bypass of TCA, malate synthase (KGT44986), isocitrate lyase (KGT44987) was down-regulated at 0.61 and 0.66 fold respectively at $48 \mathrm{~h}$ (Table 1).

Enzymes in Butanoate Metabolism Butanoyl-CoA converted from acetyl-CoA is another major carbon metabolic product. Using this pathway, bacteria can produce butanoate when grown at neutral pH on glucose [27]. The first step in this pathway is identical with PHB biosynthesis, afterward, acetoacetyl-CoA is converted to (S)-3-hydroxybutanoyl-CoA by 3-hydroxybutyryl-CoA dehydrogenase (KGT41139). The final two-step conversion of butanoyl-CoA to butanoate will provide energy source for cells, as ATP is generated. This two-step conversion process is catalyzed by phosphate butyryltransferase (KGT41693) and butyrate kinase (KGT41691). Phosphate butyryltransferase was up-regulated (1.86 fold) at $48 \mathrm{~h}$, and butyrate kinase had a higher abundance at $48 \mathrm{~h}$ compared to the other two time points (Fig. 4B, Table 1).

Enzymes in Pyruvate Fermentation. Bacillus spp. can grow by substrate-level phosphorylation/ fermentation under anoxic condition [28]. In B. cereus tsu1, formate acetyltransferase (KGT45740) and pyruvate formate lyase-activating protein (KGT45741), which catalyze the reversible conversion of pyruvate into acetyl-CoA using radical non-redox mechanism $[29,30]$, were up-regulated at 2.11 and 2.2 fold in 48h-culture (Fig. 4B, Table 1). Lactate dehydrogenase (KGT41354) catalyzing the interconversion of pyruvate to lactate was up-regulated at 1.81 fold; lactate utilization protein C (KGT44853), L-lactate dehydrogenase complex protein LIdF (KGT44852) and formate dehydrogenase (KGT45530) were upregulated at 1.84, 1.51 and 1.5 fold respectively in the same culture. For alcohol fermentation, acetyl-CoA is first converted to acetaldehyde by acetaldehyde dehydrogenase (KGT41893), and then to alcohol by ethanol-active dehydrogenase (KGT44011), the latter protein was up-regulated at 1.68 fold. The acetylCoA hydrolase (KGT44257) catalyzing the reaction producing acetate from acetyl-CoA also had the highest abundance in 48h-sample.

Enzymes in Acetoin and 2,3-Butanediol Synthesis. Acetoin or 3-hydroxybutanoate is another form of carbon and energy storage produced and excreted by bacteria when the pyruvate level is high [31]. At exponential phase, acetoin production and secretion can prevent cytoplasm and extracellular environment from over-acidification caused by acetic acid and citric acid [32]. Then at stationary phase, it can be used to provide energy for other metabolic pathways [33]. In B. cereus tsu1, acetolactate synthase catalytic subunit (KGT44244) and regulatory subunit (KGT44245), acetolactate synthase (KGT44547) and catalytic subunit (KGT44546), acetolactate synthase (KGT45211) were observed with higher abundance level in 12h-culture (Fig. 4B, Additional file 1: Table S1-3). Acetolactate decarboxylase (KGT45212) was not identified in this proteome profile. The operon comprising of acetoin-reuptake 
enzymes- acetoin dehydrogenase (KGT42181), acetoin utilization protein (KGT42182), histone deacetylase (KGT42183) were not observed with significant changes in abundance, whereas enzymes in the operon converting acetoin into acetaldehyde and acetyl-CoA were all up-regulated at $48 \mathrm{~h}$ (Table 1), which include dihydrolipoamide dehydrogenase (KGT43462, 1.72 fold), branch-chain alpha-keta acid dehydrogenase subunit E2 (KGT43463), and acetoin dehydrogenase E1 $\beta$ component (KGT43464, 1.59 fold), acetoin dehydrogenase E1a component (KGT43465, 2.59 fold). R,R-butanediol dehydrogenase (KGT45433) catalyzing the reversible oxidation of 2,3-butanediol to acetoin and the practically irreversible reduction of diacetyl to acetoin was up-regulated at 1.64 fold in $48 \mathrm{~h}$-culture [34].

Sporulation and Stress-induced Enzymes. In batch-culture process, bacteria are facing constant stresses such as nutrient depletion and suboptimal pH levels. For gram-positive bacteria like Bacillus spp., selfrescue mechanisms under nutrient limitation and environmental stress include induction of chemotaxis protein [35], production of antibiotics [36], secretion of hydrolytic enzymes [37], and finally sporulation. In 24h-sample, pre-spore and spore structures were observed; in 48h-sample, mature endospores were released, meanwhile significant PHB degradation occurred.

In the quantitative proteomic analysis of $B$. cereus tsu1, stress related proteins were identified with significant changes (Fig. 5A, Table 1). Glyoxalase/ lactoylglutathione lyase (KGT43173, KGT42737, KGT42638, KGT44383) [38], chemotaxis protein (KGT45443, KGT41216) [39], activator of Hsp90 ATPase (KGT43768) were significantly higher at $12 \mathrm{~h}$ (late exponential phase) compared to $24 \mathrm{~h}$ (stationary phase). Molecular chaperone Hsp20 (KGT44005), chaperonin (KGT45779) [7], copper resistance protein CopZ (KGT42404), and RNA-binding protein Hfq (KGT42386) [40] were significantly higher at $24 \mathrm{~h}$. Flagellar hook protein FlgL (KGT44525), flagellin (KGT44484), molecular chaperone DnaJ (KGT45678), disulfide bond formation protein DsbD (KGT45484), anti-terminator HutP (KGT42538) [41], general stress protein (KGT41365), PhoP family transcriptional regulator (KGT42051) [42], sigma-54 modulation protein (KGT40985) and stress protein (KGT43053) had the highest abundance level in 48h-culture.

Thirty-eight proteins related to sporulation were identified with significant change over time (Fig. 5A, Table 1). As the proteins interaction network displayed in Fig. 5B, chemotaxis protein CheY/Spo0A (KGT41699), sporulation sigma factor SigF (KGT41601), anti-sigma F factor (SpollAB, KGT41602); anti-sigma F factor antagonist (SpollAA, KGT41603), stage II sporulation protein E (Spoll E, KGT45993) are key enzymes involved in sporulation $[43,44]$. SigF is the essential enzyme for Bacillus spp. sporulation induction. Antisigma $\mathrm{F}$ factor is the antagonist of SigF, whose activity can be diminished by Spoll $\mathrm{E}$ under the regulation of Spo0A [45]. From our results, SigF and Spoll E were up-regulated at 1.43 fold and 1.5 fold, whereas, anti-sigma $\mathrm{F}$ factor was down-regulated at 0.65 fold in $24 \mathrm{~h}$-culture. The transition state regulator $\mathrm{Abh}$ (KGT44175) acts as a transcriptional regulator during the transition state from vegetative growth to stationary phase and sporulation [46], this protein was up-regulated at 1.75 fold and 2.75 fold in $24 \mathrm{~h}$ - and 48h-cutlures, respectively.

Aerobic Respiration and Anaerobic Respiration. In aerobic bacteria, oxidative phosphorylation is the major metabolic pathway using carbohydrate oxidation to generate ATP. Most ATP molecules are synthesized 
by five membrane-bound enzyme complexes (electron transport chain system), which include complex INADH: ubiquinone oxidoreductase/ NADH dehydrogenase [47], complex II-succinate-Q oxidoreductase/ succinate dehydrogenase [48], complex III-menaquinol-cytochrome c oxidoreductase, complex IVquinol/cytochrome c oxidase, and complex V-F0F1-ATPase (ATP synthase) $[43,49]$. Most atp operon proteins had higher abundance at early stage (12 h), and ATP synthase F0 subunits B (KGT41105) was significantly higher in 12h-sample compared to the other two time points (Table 1). In 48h-culture, complex III menaquinol-cytochrome $C$ reductase (KGT44670), complex IV--quinol oxidase subunit 2 (KGT45463, QoxA), cytochrome D ubiquinol oxidase subunit I (KGT42309, CydA) were significantly upregulated by 1.77 fold, 1.57 fold, 2.33 fold, respectively.

For Bacillus spp., the final electron acceptors can also be nitrate, nitrite, nitrous oxide other than $\mathrm{O}_{2}$ when respiration happens under anaerobic condition [50,51]. In our quantitative proteomics analysis, nitrate reductase NarG, NarH, NarJ, (KGT44113, 44114, 44115) were significantly up-regulated at 2.47, 1.92, 2.75 fold; nitrite reductase NirD, NirB (KGT44130, 44131) were up-regulated at 1.92, 2.48 fold in 48h-culture. These results indicate that, at this time point, the cellular metabolism pathways were changing towards nitrate respiration and fermentation.

\section{Discussion}

In this experiment, growth performance and PHB intracellular mobilization of $B$. cereus tsu 1 were examined when rapeseed cake substrate (RCS) was used as the sole nutrients for bacterial culture. In batch culture of $B$. cereus tsu1 in RCS, the maximum PHB was observed within $12 \mathrm{~h}$. Significant PHB degradation occurred as well as release of mature endospores in the $48 \mathrm{~h}$-culture. The bacterial growth performance in RCS was comparable with cultural media such as LB and minimal salt medium M9 supplemented with glucose, while the PHB accumulation in RCS was earlier (data not shown). The quantitative proteomic analysis of $B$. cereus tsu1 used a holistic approach to investigate the entire proteome expressed in bacterial cells at different cell growth and PHB mobilization stages. Totally 3,215 proteins were identified, out of which 2,952 proteins were quantified in all three time points. Based on PANTHER gene ontology classification, the biological processes enriched with the $24 \mathrm{~h}: 12 \mathrm{~h}$ up-regulated SCPs including purine nucleotide metabolism, protein folding, metal ion homeostasis, response to stress. The 24h:12h down-regulated SCPs were associated with carboxylic acid catabolism, cellular amino acid catabolism, peptidoglycan biosynthetic process, RNA process. In the 48h-12h pair of sample, SCPs were enriched into carbohydrate metabolism, protein metabolism, oxidative phosphorylation, formation of translation ternary structure, etc.

Enzymes for PHB biosynthesis and intracellular degradation were quantified in this proteomic analysis, even though, a majority of enzymes were not observed to have significantly abundance changes across the three cultures at 12, 24 and $48 \mathrm{~h}$. PhaC is the key enzyme in PHB polymerization [52] and a significantly higher abundance of PhaC was observed in 12h-culture. Accordingly, a shorter interval of sampling strategy should be applied in future studies of the related enzymes. PhaJ, PhaB, and enzymes using succinyl-CoA to produce PHB were all identified in 12h-culture, which is an evidence that the 
bacterium is using all three pathways for PHB accumulation [53, 54]. Additionally, the 3-oxoadipate enollactonase catalyzing PHB intracellular degradation showed the highest level in the same $12 \mathrm{~h}$-culture. Taken together, these results indicate that the PHB synthesis and utilization processes occurred simultaneously in these cells. In another research using mutant $B$. thuringiensis BMB171 as a model organism, PHB degradation remained active even when the gene encoding for 3-oxoadipate enollactonase was deleted, which implies that other enzymes are responsible for PHB degradation as well [55]. The enzyme 3-oxoadipate enol-lactonase of $B$. thuringiensis contains a lipase box-like sequence (GW-S102-M-G), and the serine (102) site was proved to be important for the PHB-hydrolyzing activity [22]. Protein BLAST of KGT42842 on NCBI classified it as an alpha/beta hydrolase superfamily protein. To look for other potential proteins contributing to PHB degradation, alpha/beta hydrolase superfamily proteins on annotated genome of $B$. cereus tsu1 were downloaded, and multiple sequence alignment were performed to compare sequence homology and to detect putative lipase box-like sequence [56]. As shown in Fig. 6, alpha/beta hydrolase family proteins KGT43118, KGT41369, KGT41644, KGT42270 were detected with G-X-S-X-G lipase-box sequence. These potential PHB degradation enzymes can become targets in future study for a higher PHB yield.

Spo0A plays a significant role in bacterial sporulation by regulating the activation of Spoll E. SpollE-RodZ complex was reported coordinating in asymmetric septum formation and SigF activation in B. subtilis [57]. Anti-sigma $\mathrm{F}$ can bind on SigF and blocks its ability to form an RNA polymerase holoenzyme (Esigma F), the function of which is eliminated by Spoll $E[58,59]$. In this study, Spoll $E$ and SigF were observed with significant up-regulation, while anti-sigma F was significantly down-regulated at $24 \mathrm{~h}$; nevertheless, the transcription factor Spo0A did not have significant abundance change across the culture period. As the concurrence of sporulation and PHB degradation was always observed in spore forming bacteria, previous studies suggested that suppression of sporulation can be used as a strategy to improve PHB yield. But in the experiment with deletion of spoOA in B. thuringiensis, the mutant was found severely impaired in PHB accumulation [45]. It was concluded that the Spo0A transcription factor is required for a global regulation of PHB biosynthesis, sporulation and other cell cycles. As the protein abundance of both Spoll E and SigF was significantly increased during forespore formation, they can be promising targets in reducing sporulation and improving PHB biosynthesis.

At $48 \mathrm{~h}$, enzymes for nitrate respiration were highly induced, which is an indicator of oxygen limitation during batch-culture [60]. At this period of time, enzymes for pyruvate fermentation into formate, lactate, ethanol were significantly induced; the abundance of phosphate butyryltransferase (KGT41693) and butyrate kinase (KGT41691) for butanoate biosynthesis reached the highest level [61]; proteins for the acetoin and butanediol metabolism were also highly induced. These pathways utilize the same carbon sources as PHB biosynthesis, which might need to consume products from PHB degradation [32]. These results concurred with the significant degradation of PHB in the cells at $48 \mathrm{~h}$.

\section{Conclusions}


Proteome profile changes during PHB intracellular mobilization in Bacillus cereus tsu1 was identified in this study. Our results revealed: 1) The key enzyme PhaC for PHB synthesis and 3-oxoadipate enollactonase for PHB degradation were detected in all samples and both reached a higher abundance in 12h-culture implying the concurrence of PHB synthesis and utilization at this time point; 2) the protein abundance level of SpollE and SigF was significantly increased to induce asymmetric septum formation and sporulation, which can be promising target genes for delaying sporulation and thus increasing PHB accumulation; 3) when oxygen became limited, enzymes for nitrate respiration and fermentation were induced to compete for the carbon resource with PHB biosynthesis.

PHB production in non-spore forming bacteria can be induced by excess carbon and imbalanced nutrients conditions (depleted nitrogen, phosphorus, and low oxygen); whereas the same condition will lead to sporulation, fermentative growth and PHB consumption in Bacillus strains. In this context, results from this study provide insights into the proteome profile changes during PHB accumulation and recycling in $B$. cereus tsu1. The identified proteins (genes) can be targeted for modification to achieve a higher PHB yield and to improve bacterial growth performance and stress resistance in Bacillus spp.

\section{Methods}

Bacterial culture. In our previous research [19, 20], we have reported the isolation and genome analysis of $B$. cereus tsu1. The genome sequence is available in NCBI database under accession No. JPYN01.

Bacillus cereus tsu 1 was cultured in $50-\mathrm{ml}$ tube containing $20 \mathrm{ml}$ rapeseed cake substrate (RCS, $2.5 \%$ aqueous extract). A fresh overnight (16 h) single-colony culture in LB broth was used as inoculum (at 1:100 ratio). Bacterial cultures were agitated at $200 \mathrm{rpm}$ and $30^{\circ} \mathrm{C}$. Cells were taken from the culture at 6 , $9,12,24,48 \mathrm{~h}$ and stained with Sudan Black to observe PHB accumulation under a microscope equipped with 506 color camera and 63X oil lens (Axioimager M2, Zeiss) [62]. Cell samples were collected at 12, 24, and $48 \mathrm{~h}$ by centrifugation at $13,000 \times \mathrm{g}$, for $5 \mathrm{~min}$. Triplicate cultures were included for each time point.

Protein sample preparation. Proteins were extracted from cell pellets using the SDS phenol based protein extraction method [63]. Briefly, frozen bacterial cell pellets were re-suspended in a buffer containing $2 \%$ sodium dodecyl sulfate (SDS), $30 \%$ sucrose, $5 \% \beta$-mercaptoethanol $(\mathrm{v} / \mathrm{w})$ prepared in $0.1 \mathrm{M} \mathrm{Tris-} \mathrm{HCl}(\mathrm{pH}$ 8.0) and ground using a Retsch Mixer Mill MM 400 (Retsch $\mathrm{GmbH}$, Germany). Cold phenol was added at $1: 1$ ratio and the samples were incubated at $4{ }^{\circ} \mathrm{C}$ for $2 \mathrm{~h}$. The mixture was centrifuged at $13,000 \times \mathrm{g} 4{ }^{\circ} \mathrm{C}$ for $20 \mathrm{~min}$, and protein in the upper phenol phase was precipitated in methanol containing $0.1 \mathrm{M}$ ammonium acetate after overnight incubation at $-20^{\circ} \mathrm{C}$. After a serial of washes in methanol followed by acetone, the air-dried protein pellets were solubilized in $100 \mathrm{mM}$ triethylammonium bicarbonate (TEAB) buffer. Protein concentration was determined using a Qubit Protein Assay Kit (Thermo Fisher Scientific, MA) on a Qubit 3.0 Fluorometer (Invitrogen, CA).

TMT labeling. For TMT labeling, a100 $\mu$ g protein sample was processed following the instructions in the TMT10plex ${ }^{\mathrm{TM}}$ Isobaric Label Reagent Set (Thermo Fisher Scientific). Protein tryptic digestion was conducted using Sequencing Grade Modified Trypsin (Promega, WI) with incubation at $37^{\circ} \mathrm{C}$ for $16 \mathrm{~h}$. 
The three replicates of bacterial samples grown for $12 \mathrm{~h}$ were labeled with tags $126,128 \mathrm{C}, 129 \mathrm{~N} ; 24 \mathrm{~h}$ samples with 127N, 131 and 129C; and $48 \mathrm{~h}$ samples with 127C, 130N, 128N [64]. After combining all the labeled samples, SDS and nonionic solvents were removed using Oasis MCX cartridge following the manufacturer's instructions (Waters; MA). Peptides were eluted in $75 \%$ acetonitrile (CAN) $/ 10 \% \mathrm{NH}_{4} \mathrm{OH}$ and dried at reduced pressure using a CentiVac Concentrator (labConco, MO). Prior to reconstitution for analysis by mass spectrometry, the samples were re-suspended in $100 \mu$ l deionized water and re-dried.

Nano LC-MS/MS analysis. The high pH reverse phase high performance liquid chromatography (hpRPHPLC) was carried out using a Dionex UltiMate 3000 HPLC system with the built-in micro fraction collection option in its autosampler and UV detection (Sunnyvale, $C A$ ) as reported previously [65]. The TMT 10-plex tagged tryptic peptides were reconstituted in buffer $\mathrm{A}(20 \mathrm{mM}$ ammonium formate $\mathrm{pH} 9.5 \mathrm{in}$ water), and loaded onto an XTerra MS C18 column (3.5 $\mu \mathrm{m}, 2.1 \times 150 \mathrm{~mm})$ (Waters ,Milford, MA) with buffer $\mathrm{A}$ and $80 \% \mathrm{ACN} / 20 \% 20 \mathrm{mM} \mathrm{NH4FA}$ as buffer B. Liquid chromatography (LC) was performed using a gradient from $10-45 \%$ of buffer $B$ for 30 min at a flow rate $200 \mu \mathrm{L} / \mathrm{min}$. Forty-eight fractions were collected at $1 \mathrm{~min}$ intervals and pooled into a total of 12 fractions based on the UV absorbance at $214 \mathrm{~nm}$ and with multiple fraction concatenation strategy [66]. All of the fractions were dried and reconstituted in $100 \mu \mathrm{L}$ of $2 \%$ ACN/0.5\% FA for Nano LC-MS/MS analysis.

The Nano LC-MS/MS analysis was carried out using an Orbitrap Fusion (Thermo Fisher Scientific) mass spectrometer equipped with nano ion source using high energy collision dissociation (HCD) similar to previous reports [67]. The Orbitrap is coupled with the UltiMate 3000 RSLCnano (Dionex, CA). Each reconstituted fraction $(8 \mu \mathrm{L})$ was injected onto a PepMap C-18 RP nano trap column $(3 \mu \mathrm{m}, 75 \mu \mathrm{m}$ X 20 $\mathrm{mm}$, Dionex) with nanoViper Fittings at $20 \mathrm{~L} / \mathrm{min}$ flow rate for on-line desalting and then separated on a PepMap C-18 RP nano column ( $3 \mu \mathrm{m}, 75 \mu \mathrm{m} \times 15 \mathrm{~cm})$, and eluted in a 120 min gradient of $5 \%$ to $38 \%$ acetonitrile (ACN) in $0.1 \%$ formic acid at $300 \mathrm{~nL} / \mathrm{min}$, followed by a 7-min ramping to $95 \% \mathrm{ACN}-0.1 \% \mathrm{FA}$ and a 7-min hold at 95\% ACN-0.1\% FA. The column was re-equilibrated with $2 \%$ ACN-0.1\% FA for 20 min prior to the next run. The Orbitrap Fusion was operated in positive ion mode with nano spray voltage set at $1.6 \mathrm{kV}$ and source temperature at $275^{\circ} \mathrm{C}$. External calibration for FT, IT and quadrupole mass analyzers was performed. An internal calibration was performed using the background polysiloxane ion signal at $\mathrm{m} / \mathrm{z} 445.120025$ as the calibrant. The instrument was operated in data-dependent acquisition (DDA) mode using FT mass analyzer for one survey MS scan for selecting precursor ions followed by Top 3 second data-dependent HCD-MS/MS scans for precursor peptides with 2-7 charged ions above a threshold ion count of 10,000 with normalized collision energy of $37.5 \%$. MS survey scanned at a resolving power of 120,000 (fwhm at $\mathrm{m} / \mathrm{z} 200$ ), for the mass range of $\mathrm{m} / \mathrm{z} 400-1600$ with $A G C=3 e 5$ and Max IT = $50 \mathrm{~ms}$, MS/MS scanned at 50,000 resolution with AGC=1e5, Max IT $=120 \mathrm{~ms}$ and with Q isolation window $(\mathrm{m} / \mathrm{z})$ at 1.6 for the mass range $\mathrm{m} / \mathrm{z} 105-2000$. Dynamic exclusion parameters were set at 1 within 50 s exclusion duration with $\pm 10 \mathrm{ppm}$ exclusion mass width. All data was acquired under Xcalibur 3.0 operation software and Orbitrap Fusion Tune 2.0 (Thermo Fisher Scientific).

Protein identification and quantification. All MS/MS raw spectra were processed and database searched using Sequest HT software within the Proteome Discoverer 2.2 (PD 2.2, Thermo Fisher Scientific). 
Bacillus cereus tsu1 protein database (which was constructed using six-frame translation of the assembled genome sequence) was used to search the spectra (database download link: https://www.ncbi.nlm.nih.gov/protein?linkname=bioproject_protein\&from_uid=256220). The search parameters were: two mis-cleavages for full trypsin with fixed carbamidomethyl of cysteine, fixed 10-plex TMT modifications on lysine and $\mathrm{N}$-terminal amines and variable modifications of methionine oxidation and deamidation on asparagine and glutamine residues. The peptide mass tolerance and fragment mass tolerance values were $10 \mathrm{ppm}$ and $50 \mathrm{mDa}$, respectively. Identified peptides were filtered for maximum $1 \%$ FDR using the Percolator algorithm in PD 2.2 along with peptide confidence set to high. The TMT10-plex quantification method within PD 2.2 was used to calculate the reporter ratios with a mass tolerance \pm 10 ppm without applying isotopic correction factors. Only peptide spectra containing all reporter ions were designated as "quantifiable spectra" and used for peptide/protein quantitation. A protein ratio was expressed as a median value of the ratios for all quantifiable spectra of the unique peptides pertaining to that protein. For each relative ratio group, normalization on protein median was applied.

Significantly changed proteins (SCPs) identification. For protein quantification analysis it requires that a protein is reported with two or more unique peptides across all biological samples. The $\log _{2}$-transformed abundance of all constituent peptides of proteins identified with at least two unique peptides were subjected to a quantification study using t-test (General Linear Model) followed by false discovery rate (FDR) analysis. The $\log _{2}$ ratios of peptides were fitted to a normal distribution, one and half standard deviations ( \pm 1.5 SD, i.e., a $90 \%$ confidence level) and a FDR adjusted $p$-value $\leq 0.05$ were used as the cutoff threshold values for significantly changed proteins. SCPs fold changes were obtained from anti-log conversion of $\log _{2}$ ratios. The statistical analysis was conducted using SAS (version 9.4) [68].

PANTHER and STRING Analysis. Gene Ontology (GO) functional classification of 24-12h pair, and 48-12h pair SCPs was performed using the PANTHER classification system (v.14.1, http://www.pantherdb.org). The gene IDs of SCPs were submitted to the database to carry out PANTHER Overrepresentation test using the PANTHER GO-Slim Biological Process [69]. Proteins assigned to at least one category could be counted more than once. The STRING database (10.5, https://version-10-5.string-db.org) was used to predict protein-protein interaction networks based on certain active interaction sources including textmining, experiments, database, co-expression, neighborhood, gene fusion, co-occurrence [70]. Network analysis was performed by submitting SCPs sequences to the STRING database. Medium confidence (0.400) was applied and disconnected nodes were hidden. Protein clusters were created using the Markov Cluster Algorithm $(\mathrm{MCL})$ inflation parameter $(\mathrm{MCL}=3)$. Lines between nodes represent their action effects, while continuous lines representing direct interactions, interrupted lines indicating indirect functional connections. Protein sequences of functionally enriched proteins were subjected to illustrate the possible molecular actions between each other.

\section{Abbreviations}

PHB: poly-hydroxybutyrate 
RCS: Rapeseed Cake Substrate

B. cereus: Bacillus cereus

SigF: Sigma factor $F$

SpoE II: Stage II sporulation protein E

SCPs: Significantly Changed Proteins

PHAs: Poly-hydroxyalkanoates

DO: Dissolved Oxygen

TMT: Tandem Mass Tags

FDR: False Discovery Rate

EMP: Embden-Meyerhof-Parnas

PP: Pentose Phosphate

TCA: Tricarboxylic Acid Cycle

ATP: Adenosine Triphosphate

BLAST: Basic Local Alignment Search Tool

B. subtilis: Bacillus subtilis

B. thuringiensis: Bacillus thuringiensis

STRING: Search Tool for the Retrieval of Interacting Genes

MCL: Markov Cluster Algorithm

\section{Declarations}

Ethics approval and consent to participate

Not applicable.

Consent for publication

Not applicable.

Availability of data and materials 
The mass spectrometry proteomics data were deposited to the ProteomeXchange database (http://proteomexchange.org/) via the PRIDE partner repository with identifier PXD009960 under project title: TMT-quantitative proteomic study of Bacillus cereus tsu1. All other data generated or analyzed during this study are included in this manuscript.

\section{Competing interests}

The authors declare that they have no competing interests.

ARS disclaimer: "Mention of trade names or commercial products in this publication is solely for the purpose of providing specific information and does not imply recommendation or endorsement by the U.S. Department of Agriculture. The funders of the project had no role in study design, data collection and interpretation, or the decision to submit the work for publication.

\section{Funding}

This research was supported by the National Institutes of Food and Agriculture (NIFA), U.S. Department of Agriculture, grant number 2018-38821-27737 for the 1890 Capacity Building Grants Program.

\section{Authors' contributions}

HL, ST, SZ designed the study and performed quantitative proteomic experiment; TF, YY performed Mass Spectrometry analysis; HL, JO performed SAS statistical analysis; HL wrote the manuscript; SB, SZ, and TT critically reviewed and edited drafts of the manuscript and gave important suggestions on interpretation of results and discussion. All authors have read and approved the manuscript.

\section{Acknowledgements}

The authors wish to thank Dr. Sheng Zhang of the Proteomics and Mass Spectrometry Facility at the Cornell University Institute of Biotechnology for expert technical assistance and helpful discussions for the proteomics analysis. We also thank Dr. Jason P. de Koff for kindly providing rapeseed cake materials and Mr. Dwane Adams for professional instructions in using the imaging system.

\section{Author Information}

Department of Agricultural and Environmental Sciences, College of Agriculture, Tennessee State University, 3500 John Merritt Blvd, Nashville, TN 37209, U.S.

Hui Li, Joshua O'Hair, Santosh Thapa, Sarabjit Bhatti, Suping Zhou

R.W. Holley Center for Agriculture and Health, USDA-ARS, Cornell University, Ithaca, NY 148532, U.S.

Yong Yang, Tara Fish, Theodore W. Thannhauser

\section{Corresponding authors}

Page 14/28 


\section{References}

1. Zigha A, Rosenfeld E, Schmitt P, Duport C. The Redox Regulator Fnr Is Required for Fermentative Growth and Enterotoxin Synthesis in Bacillus cereus F4430 / 73. J Bacteriol. 2007;189:2813-2824. http://doi.org/10.1128/JB.01701-06.

2. Kumar P, Patel SKS., Lee JK, Kalia VC. Extending the limits of Bacillus for novel biotechnological applications. Biotechnol Adv. 2013;31(8):1543-1561. doi:10.1016/j.biotechadv.2013.08.007.

3. Łabużek S, Radecka I. Biosynthesis of PHB tercopolymer by Bacillus cereus Journal of Applied Microbiology. 2001;90:353-357. https://doi.org/10.1046/j.1365-2672.2001.01253.x.

4. Keshavarz T, Roy I. Polyhydroxyalkanoates: bioplastics with a green agenda. Curr Opin Microbiol. 2010;13:321-326. http://doi.org/10.1016/j.mib.2010.02.006.

5. Park SJ, Lee SY, Lee Y. Biosynthesis of (R)-3-Hydroxyalkanoic Acids by Metabolically Engineered Escherichia coli. In: Finkelstein M., McMillan J.D., Davison B.H., Evans B. (eds), Biotechnology for Fuels and Chemicals (The Twenty-Fifth Symposium). Totowa: Humana Press; 2004.

6. Chen G. A microbial polyhydroxyalkanoates (PHA) based bio- and materials industry. Chem Soc Rev. 2009;38(8):2434-2446. http://doi.org/10.1039/b812677c.

7. Wu D, He J, Gong Y, Chen D, Zhu X, Qiu N, Sun M, Li M, Yu Z. Proteomic analysis reveals the strategies of Bacillus thuringiensis YBT-1520 for survival under long-term heat stress. Proteomics. 2011;11:2580-2591. http://doi.org/10.1002/pmic.201000392.

8. Antelmann H, Sapolsky R, Miller B, Ferrari E, Chotani G, Weyler W, Gaertner A, Hecker M. Quantitative proteome profiling during the fermentation process of pleiotropic Bacillus subtilis Proteomics. 2004;4:2408-2424. http://doi.org/10.1002/pmic.200300752.

9. Mizuno K, Kihara T, Tsuge T, et al. Cloning and heterologous expression of a novel subgroup of class IV polyhydroxyalkanoate synthase genes from the genus Bacillus. Biosci Biotechnol Biochem. 2017;8451:1-3. doi:10.1080/09168451.2016.1230006.

10. Uchino K, Saito T, Gebauer B, Jendrossek D. Isolated Poly(3-Hydroxybutyrate) (PHB) Granules Are Complex Bacterial Organelles Catalyzing Formation of PHB from Acetyl Coenzyme A (CoA) and Degradation of PHB. J Bacteriol. 2007;189(22):8250-8256. doi:10.1128/JB.00752-07.

11. Piggot PJ, Hilbert DW. Sporulation of Bacillus subtilis. Curr Opin Microbiol. 2004;7:579-586. http://doi.org/10.1016/j.mib.2004.10.001.

12. Cohn R. Bacillus subtilis and its relatives: molecular biological and industrial workhorses. Trends Biotechnol. 1992;10:247-256. https://doi.org/10.1016/0167-7799(92)90233-L.

13. Ray S, Kalia VC. Polyhydroxyalkanoate Production and Degradation Patterns in Bacillus Indian J Microbiol. 2017;10:247-256. http://doi.org/10.1007/s12088-017-0676-y.

14. Sadykov MR, Ahn J, Widhelm TJ, Eckrich VM, Endres JL, Driks A, Rutkowski GE, Wingerd KL, Bayles KW. Poly(3-hydroxybutyrate) fuels the tricarboxylic acid cycle and de novo lipid biosynthesis during 
Bacillus anthracis Mol Microbiol. 2017;104:793-803. http://doi.org/10.1111/mmi.13665.

15. Chumsakul O, Anantsri DP, Quirke T, Oshima T, Nakamura K, Ishikawa S, Nakano MM. Genome-wide analysis of ResD, NsrR, and Fur binding in Bacillus subtilisduring anaerobic fermentative growth by in vivo J Bacteriol. 2017;199:e00086-17. https://doi.org/10.1128/JB.00086-17.

16. Ye RW, Tao W, Bedzyk L, Young T, Chen M. Global Gene Expression Profiles of Bacillus subtilis Grown under Anaerobic Conditions. J Bacteriol. 2000;182:4458-4465.

https://doi.org/10.1128/JB.182.16.4458-4465.2000.

17. Clements LD, Streips UN, Miller BS. Differential proteomic analysis of Bacillus subtilis nitrate respiration and fermentation in defined medium. Proteomics. 2002;2:1724-1734. https://doi.org/10.1002/1615-9861(200212)2:12<1724::AID-PROT1724>3.0.CO;2-S.

18. Faccin DJL, Rech R, Secchi AR, Cardozo NSM, Ayub MAZ. Influence of oxygen transfer rate on the accumulation of poly(3-hydroxybutyrate) by Bacillus megaterium. Process Biochem. 2013;48(3):420425. doi:10.1016/j.procbio.2013.02.004.

19. Li H, Zhou S, Johnson T, Vercruysse K, Ropelewski AJ, Thannhauser W. Draft Genome Sequence of a New Bacillus cereus Strain tsu1. Genome Announcements. 2014;2:e01294-14. http://doi.org/10.1128/genomeA.01294-14.

20. Li H, Zhou S, Johnson T, Vercruysse K, Lizhi O, Ranganathan P, Phambu N, Ropelewski AJ, Thannhauser TW. Genome Structure of Bacillus cereus tsu1 and Genes Involved in Cellulose Degradation and Poly-3-Hydroxybutyrate Synthesis, International Journal of Polymer Science. 2017;2017:6192924. https://doi.org/10.1155/2017/6192924.

21. Chen D, Xu D, Li M, He J, Gong Y, Wu D. Proteomic analysis of Bacillus thuringiensis $\triangle$ phaC mutant BMB171 / PHB-1 reveals that the PHB synthetic pathway warrants normal carbon metabolism. J Proteomics. 2012;75:5176-5188. http://doi.org/10.1016/j.jprot.2012.06.002.

22. Tseng $\mathrm{C}$, Chen $\mathrm{H}$, Shaw G. Identification and Characterization of the Bacillus thuringiensis phaZ Gene, Encoding New Intracellular Poly-3-Hydroxybutyrate Depolymerase. J Bacteriol. 2006;188:7592-7599. http://doi.org/10.1128/JB.00729-06.

23. Hyakutake M, Saito Y, Tomizawa S, Mizuno K. Polyhydroxyalkanoate ( PHA) Synthesis by Class IV PHA Synthases Employing Ralstonia eutropha PHB 4 as Host Strain. J Bioscience, Biotechnology, and Biochemistry. 2014;75: 1615-1617. http://doi.org/10.1271/bbb.110229.

24. Quelas JI, Mesa S, Mongiardini EJ, Jendrossek D, Lodeiro AR. Regulation of Polyhydroxybutyrate Synthesis in the Soil Bacterium Bradyrhizobium diazoefficiens. Appl Environ Microbiol. 2016;82:4299-4308. http://doi.org/10.1128/AEM.00757-16.

25. Tajima K, Igari T, Nishimura D, Nakamura M, Satoh Y, Munekata M. Isolation and Characterization of Bacillus sp. INTO05 accumulating Polyhydroxyalkanoate (PHA) from Gas Field Soil. J Biosci Bioeng. 2003;95:77-81. https://doi.org/10.1016/S1389-1723(03)80152-4.

26. Ireton K, Jint S, Grossman AD, Sonensheintt L. Krebs cycle finction is required for activation of the Spo0A transcription factor in Bacillus subtilis. PNAS. 1995;92:2845-2849. https://doi.org/10.1073/pnas.92.7.2845. 
27. Bennett GN, Rudolph FB. The central metabolic pathway from acetyl-CoA to butyryl-CoA in Clostridium acetobutylicum. FEMS Microbiology Rev. 1995;17:241-249. https://doi.org/10.1111/j.1574-6976.1995.tb00208.x.

28. Nakano MM, Dailly YP, Zuber P, Clark DP. Characterization of Anaerobic Fermentative Growth of Bacillus subtilis. Identification of Fermentation End Products and Genes Required for Growth. J Bacteriol. 1997;179:6749-6755. http://doi.org/10.1128/jb.179.21.6749-6755.1997.

29. Marsh ENG. A radical approach to enzyme catalysis. BioEssays. 1995;17:431-441. https://doi.org/10.1002/bies.950170511.

30. Wolfe AJ. The Acetate Switch. Microbiol Mol Biol Rev. 2005;69:12-50. http://doi.org/10.1128/MMBR.69.1.12

31. Speck EL, Freese E. Control of Metabolite Secretion in Bacillus subtilis. Journal of General Microbiol. 1973;78:261-275. http://doi.org/1099/00221287-78-2-261.

32. Kominek LA, Halvorson HO. Metabolism of Poly-beta-Hydroxybutyrate and Acetoin in Bacillus cereus. J Bacteriol. 1965;90:1251-1259.

33. Yang S, Dunman PM, Projan SJ, Bayles KW. Characterization of the Staphylococcus aureus CidR regulon: elucidation of a novel role for acetoin metabolism in cell death and lysis. Molecular Microbiol. 2006;60:458-468. http://doi.org/10.1111/j.1365-2958.2006.05105.x.

34. Zhang X, Bao T, Rao Z, Yang T, Xu Z, Yang S. Two-Stage pH Control Strategy Based on the pH Preference of Acetoin Reductase Regulates Acetoin and 2,3-Butanediol Distribution in Bacillus subtilis, Plos one. 2014;9:e91187. http://doi.org/10.1371/journal.pone.0091187.

35. Maurer LM, Yohannes E, Bondurant SS, Radmacher M, Slonczewski JL. pH Regulates Genes for Flagellar Motility, Catabolism, and Oxidative Stress in Escherichia coli K-12†. J Bacteriol. 2005;187:304-319. http://doi.org/10.1128/JB.187.1.304.

36. Hibbing ME, Fuqua C, Parsek MR, Peterson SB. Bacterial competition: surviving and thriving in the microbial Jungle. Nat Rev Microbiol. 2010;8:15-25. http://doi.org/10.1038/nrmicro2259.Bacterial

37. Szilagyi M, Miskei M, Karanyi Z, Lenkey B, Pocsi I, Emri T. Transcriptome changes initiated by carbon starvation in Aspergillus nidulans. Microbiology. 2013;159:176-190. http://doi.org/10.1099/mic.0.062935-0.

38. Leelakriangsak M, Thi N, Huyen T, Töwe S, van Duy N, Becher D, Hecker M, Antelmann H, Zuber P. Regulation of quinone detoxification by the thiol stress sensing DUF24/MarR-like repressor, YodB in Bacillus subtilis. Mol Microbiol. 2008;67:1108-1124. http://doi.org/10.1111/j.13652958.2008.06110.x.

39. Schmid R, Graumann P, Schro K. Cold Shock Stress-Induced Proteins in Bacillus subtilis. J Bacteriol. 1996;178:4611-4619. http://doi.org/10.1128/jb.178.15.4611-4619.1996.

40. Christiansen JK, Larsen MH, Ingmer H, Søgaard-andersen L, Kallipolitis BH. The RNA-Binding Protein Hfq of Listeria monocytogenes: Role in Stress Tolerance and Virulence. J Bacteriol. 2004;186:33553362. http://doi.org/10.1128/JB.186.11.3355. 
41. Gopinath SCB, Balasundaresan D, Kumarevel T, Misono TS, Mizuno H, Kumar PKR. Insights into antitermination regulation of the hut operon in Bacillus subtilis: importance of the dual RNA-binding surfaces of HutP. Nucleic Acids Res. 2008;36:3463-3473. http://doi.org/10.1093/nar/gkn199.

42. Hulett FM. The signal-transduction network for Pho regulation in Bacillus subtilis. Mol Microbiol. 1996;19:933-939. https://doi.org/10.1046/j.1365-2958.1996.421953.x.

43. Wang J, Mei H, Zheng C, Qian H, Cui C, Fu Y,Su J, Liu Z, Yu Z, He J. The Metabolic Regulation of Sporulation and Parasporal Crystal Formation in Bacillus thuringiensis Revealed by Transcriptomics and Proteomics. Mol Cell Proteomics. 2013;12:1363-1376.

http://doi.org/10.1074/mcp.M112.023986.

44. Higgins D, Dworkin J. Recent progress in Bacillus subtilis FEMS Microbiol Rev. 2012;36:131-148. http://doi.org/10.1111/j.1574-6976.2011.00310.x.

45. Chen H, Tsai T, Pan S, Lin J, Tseng C, Shaw G. The master transcription factor Spo0A is required for poly(3-hydroxybutyrate) (PHB) accumulation and expression of genes involved in PHB biosynthesis in Bacillus thuringiensis. FEMS Microbiol Lett. 2010;304:74-81. http://doi.org/10.1111/j.15746968.2009.01888.x.

46. Strauch MA, Perego M, Burbulys D. The transition state transcription regulator AbrB of Bacillus subtilis is autoregulated during vegetative growth. Mol Microbiol. 1989;3:1203-1209. https://doi.org/10.1111/j.1365-2958.1989.tb00270.x.

47. Friedrich T, Weiss H. Modular Evolution of the Respiratory NADH: Ubiquinone Oxidoreductase and the Origin of its Modules. J Theor Biol. 1997;187:529-540. https://doi.org/10.1006/jtbi.1996.0387.

48. Hederstedt L, Rutberg L. Biosynthesis and Membrane Binding of Succinate Dehydrogenase in Bacillus subtilis. J Bacteroil. 1980;144:941-951.

49. Hicks DB, Wang Z, Wei Y, Kent R, Guffanti AA, Banciu H, Bechhofer DH, Krulwich TA. A tenth atpgene and the conserved atp/gene of a Bacillus atp operon have a role in Mg2+ uptake. PNAS. 2003;100(18):10213-10218; https://doi.org/10.1073/pnas.1832982100.

50. Morozkina E V, Zvyagilskaya RA. Nitrate Reductases: Structure, Functions, and Effect of Stress Factors. Biochemistry (Moscow). 2007;72:1151-1160. /S0006297907100124.

51. Downey, R. J. Nitrate Reductase and Respiratory Adaptation in Bacillus stearothermophilus. J Bacteroil. 1966;91(2):634-641.

52. Tsuge T, Hyakutake M, Mizuno K. Class IV polyhydroxyalkanoate (PHA) synthases and PHAproducing Bacillus. Appl Microbiol Biotechnol. 2015;99:6231-6240. http://doi.org/10.1007/s00253015-6777-9.

53. Davis R, Anikumar PK, Chandrashekar A, Shamala TR. Biosynthesis of polyhydroxyalkanoates copolymer in coli using genes from Pseudomonas and Bacillus. Antonie Van Leeuwenhoek. 2008;94:207-216. http://doi.org/10.1007/s10482-008-9233-3.

54. Kihara T, Hiroe A, Ishii-hyakutake M, Mizuno K. Bacillus cereus type polyhydroxyalkanoate biosynthetic gene cluster contains R-specific enoyl-CoA hydratase gene. Biosci Biotechnol Biochem. 2017;81:1627-1635. http://doi.org/10.1080/09168451.2017.1325314. 
55. Wang X, Li Z, Li X, Qian H, Cai X, Li X, He J. Poly- $\beta$-hydroxybutyrate Metabolism Is Unrelated to the Sporulation and Parasporal Crystal Protein Formation in Bacillus thuringiensis. Front. Microbiol. 2016;7:1-9. http://doi.org/10.3389/fmicb.2016.00836.

56. Ho Y, Ju E, Kyum S, Seok Y, Kim J, Dae H, Kim H. Biochemical and Biophysical Research Communications Molecular cloning and characterization of a novel family VIII alkaline esterase from a compost metagenomic library. Biochem Biophys Res Commun. 2010;393:45-49. http://doi.org/10.1016/j.bbrc.2010.01.070.

57. Muchová K, Chromiková Z, Bradshaw N, Wilkinson AJ. Morphogenic Protein RodZ Interacts with Sporulation Specific SpollE in Bacillus subtilis. Plos one. 2016;11:e0159076. http://doi.org/10.1371/journal.pone.0159076.

58. Dufour A, Haldenwang WG. Interactions between a Bacillus subtilis Anti-sigma Factor (RsbW) and Its Antagonist (RsbV). J Bacteriol. 1994;176:1813-1820. http://doi/org/10.1128/jb.176.7.18131820.1994.

59. Carniol K, Ben-yehuda S, King N, Losick R. Genetic Dissection of the Sporulation Protein SpollE and Its Role in Asymmetric Division in Bacillus subtilis. J Bacteriol. 2005;187:3511-3520. http://doi.org/10.1128/JB.187.10.3511.

60. Nakano MM, Zuber P, Glaser P, Danchin A. Two-Component Regulatory Proteins ResD-ResE Are Required for Transcriptional Activation of fnr upon Oxygen Limitation in Bacillus subtilis. J Bacteriol. 1996;178:3796-3802. http://doi.org/10.1128/jb.178.13.3796-3802.1996.

61. Walter KA, Nair R V, Caryb JW, Bennettc GN, Papoutsakis ET. Sequence and arrangement of two genes of the butyrate-synthesis of Clostridium acetobutylicum ATCC 824. Gene. 1993;134:107-111. https://doi.org/10.1016/0378-1119(93)90182-3.

62. Wei Y, Chen W, Huang C, Wu H, Sun Y. Screening and Evaluation of Polyhydroxybutyrate-Producing Strains from Indigenous Isolate Cupriavidus taiwanensis Int J Mol Sci. 2011;12:252-265. http://doi.org/10.3390/ijms12010252.

63. Ye Z, Sangireddy S, Okekeogbu I, Zhou S, Yu C, Hui D, Howe KJ, Fish T, Thannhauser TW. DroughtInduced Leaf Proteome Changes in Switchgrass Seedlings. Int J Mol Sci. 2016;17:1251. http://doi.org/10.3390/ijms17081251.

64. Rangu M, Ye Z, Bhatti S, Zhou S, Yang Y, Fish T, Thannhauser TW. Association of Proteomics Changes with Al-Sensitive Root Zones in Switchgrass. Proteomes. 2018;6:15. http://doi.org/10.3390/proteomes6020015.

65. Yang Y, Qiang X, Owsiany K, Zhang S, Thannhauser TW, Li L. Evaluation of Different Multidimensional LC-MS/MS Pipelines for Isobaric Tags for Relative and Absolute Quantitation (iTRAQ)-Based Proteomic Analysis of Potato Tubers in Response to Cold Storage. J Proeome Res. 2011;10:4647-4660. http://doi.org/10.1021/pr200455s.

66. Chen JW, Scaria J, Mao C, Sobral B, Zhang S, Lawley T, Chang YF. Proteomic Comparison of Historic and Recently Emerged Hypervirulent Clostridium difficile J Proteome Res. 2013;12:1151-1161. http://doi.org/10.1021/pr3007528. 
67. Yang QS, Wu JH, Li CY, Wei YR, Sheng O, Hu CH, Kuang RB, Huang YH, Peng XX, McCardle JA, Chen W, Yang Y, Rose JK, Zhang S, Yi GJ. Quantitative Proteomic Analysis Reveals that Antioxidation Mechanisms Contribute to Cold Tolerance in Plantain (Musa paradisiaca L.; ABB Group) Seedlings. Mol Cell Proteomics. 2012;11:1853-1869. http://doi.org/10.1074/mcp.M112.022079.

68. Harrington PDB, Vieira NE, Espinoza J, Kae J, Romero R, Yergey AL. Analysis of variance-principal component analysis: A soft tool for proteomic discovery. Analytical Chimica Acta. 2005;544:118127. http://doi.org/10.1016/j.aca.2005.02.042.

69. Mi H, Muruganujan A, Huang X, Guo X, Thomas PD. Protocol Update for large-scale genome and gene function analysis with the PANTHER. Nature Protocols. 2016;14:703-721. http://doi.org/10.1038/s41596-019-0128-8.

70. Sharma D., Singh R., Deo N, Bishta D. Interactome analysis of Rv0148 to predict potential targets and their pathways linked to aminoglycosides drug resistance: An insilico approach. Microbial Pathogenesis. 2018;121:179-183. https://doi.org/10.1016/j.micpath.2018.05.034.

\section{Tables}

Table 1 Significantly changed proteins in $24 \mathrm{~h}-12 \mathrm{~h}$ and $48 \mathrm{~h}-12 \mathrm{~h}$ samples related with carbohydrate metabolism, stress, sporulation, and energy metabolism. 


\begin{tabular}{|c|c|c|c|c|}
\hline Function & Accession & Protein description & $\begin{array}{c}\text { Fold } \\
\text { Change } \\
(24 \mathrm{~h}: 12 \mathrm{~h})\end{array}$ & $\begin{array}{c}\text { Fold } \\
\text { Change } \\
\text { (48h:12h) }\end{array}$ \\
\hline \multirow[t]{23}{*}{$\begin{array}{c}\text { Carbohydrate } \\
\text { Metabolism }\end{array}$} & KGT44865 & $\begin{array}{l}\text { poly(R)-hydroxyalkanoic acid } \\
\text { synthase }\end{array}$ & 0.75 & 4 \\
\hline & KGT41362 & glucose-6-phosphate isomerase & 0.7 & 0.58 \\
\hline & KGT42918 & $\begin{array}{l}\text { 6-phosphogluconate } \\
\text { dehydrogenase }\end{array}$ & $\overline{0}$ & 0.66 \\
\hline & KGT44986 & malate synthase & 0 & 0.61 \\
\hline & KGT44987 & isocitrate lyase & ए & 0.66 \\
\hline & KGT41693 & phosphate butyryltransferase & प & 1.86 \\
\hline & KGT45740 & formate acetyltransferase & $\overline{0}$ & 2.11 \\
\hline & KGT45741 & $\begin{array}{l}\text { pyruvate formate lyase-activating } \\
\text { protein }\end{array}$ & प & 2.2 \\
\hline & KGT41354 & lactate dehydrogenase & ए & 1.81 \\
\hline & KGT44852 & amino acid dehydrogenase & प & 1.51 \\
\hline & KGT44853 & lactate utilization protein $\mathrm{C}$ & प & 1.84 \\
\hline & KGT45530 & oxidoreductase & प & 1.5 \\
\hline & KGT44011 & $\begin{array}{l}\text { ethanol-active } \\
\text { dehydrogenase/acetaldehyde- } \\
\text { active reductase }\end{array}$ & $\overline{0}$ & 1.68 \\
\hline & KGT43462 & dihydrolipoamide dehydrogenase & ए & 1.72 \\
\hline & KGT43464 & pyruvate dehydrogenase & 1.42 & 1.59 \\
\hline & KGT43465 & $\begin{array}{l}\text { acetoin:2,6- } \\
\text { dichlorophenolindophenol } \\
\text { oxidoreductase subunit alpha }\end{array}$ & 2.06 & 2.5 \\
\hline & KGT45608 & $\begin{array}{l}\text { 4-aminobutyrate } \\
\text { aminotransferase }\end{array}$ & ए & 0.65 \\
\hline & KGT40985 & sigma-54 modulation protein & ए & 1.54 \\
\hline & KGT44547 & acetolactate synthase & $\overline{0}$ & 0.65 \\
\hline & KGT44564 & 2-hydroxyacid dehydrogenase & प & 1.52 \\
\hline & KGT45433 & butanediol dehydrogenase & प & 1.64 \\
\hline & KGT42393 & butanol dehydrogenase & 0.75 & प \\
\hline & KGT42476 & dipicolinate synthase subunit A & 0.68 & 0.57 \\
\hline \multirow[t]{15}{*}{ Stress } & KGT43173 & glyoxalase & 0.6 & 0.43 \\
\hline & KGT42737 & glyoxalase & 0.68 & 0.56 \\
\hline & KGT42638 & glyoxalase & प & 0.64 \\
\hline & KGT44383 & glyoxalase & 0.46 & 0.29 \\
\hline & KGT45443 & chemotaxis protein & 0.76 & प \\
\hline & KGT41216 & chemotaxis protein & 0.7 & 0.56 \\
\hline & KGT43768 & $\begin{array}{l}\text { activator of Hsp90 ATPase } 1 \\
\text { family protein }\end{array}$ & 0.75 & प \\
\hline & KGT44005 & molecular chaperone Hsp20 & 2.29 & 2.54 \\
\hline & KGT45779 & chaperonin & 1.35 & प \\
\hline & KGT42404 & copper resistance protein CopZ & 1.43 & ए \\
\hline & KGT42386 & RNA-binding protein Hfq & 1.46 & 1.89 \\
\hline & KGT44525 & flagellar hook protein FlgL & प & 1.77 \\
\hline & KGT44484 & flagellin & प & 1.61 \\
\hline & KGT45678 & molecular chaperone DnaJ & $\overline{0}$ & 1.86 \\
\hline & KGT45484 & $\begin{array}{l}\text { disulfide bond formation protein } \\
\text { DsbD }\end{array}$ & प & 1.74 \\
\hline
\end{tabular}




\begin{tabular}{|c|c|c|c|c|}
\hline Function & Accession & Protein description & $\begin{array}{c}\text { Fold } \\
\text { Change } \\
\text { (24h:12h) }\end{array}$ & $\begin{array}{c}\text { Fold } \\
\text { Change } \\
\text { (48h:12h) }\end{array}$ \\
\hline & KGT42538 & anti-terminator HutP & 0 & 1.52 \\
\hline & KGT41365 & general stress protein & ए & 1.67 \\
\hline & KGT42051 & $\begin{array}{l}\text { PhoP family transcriptional } \\
\text { regulator }\end{array}$ & प & 1.58 \\
\hline & KGT43053 & stress protein & प & 1.59 \\
\hline \multirow[t]{38}{*}{ Sporulation } & KGT40972 & cell division protein FtsX & 0.75 & Q \\
\hline & KGT41025 & peptidase M24 & 0.65 & 0.48 \\
\hline & KGT41076 & stage III sporulation protein D & 0.61 & 0.31 \\
\hline & KGT41078 & peptidase M23 & 0.59 & 0.45 \\
\hline & KGT41184 & spore gernimation protein GerQ & 1.42 & Q \\
\hline & KGT41268 & sporulation protein & 1.66 & ए] \\
\hline & KGT41433 & cell division protein FtsQ & 0.61 & 0.54 \\
\hline & KGT41447 & DNA-binding protein & प & 0.48 \\
\hline & KGT41601 & sporulation sigma factor SigF & 1.43 & प \\
\hline & KGT41602 & anti-sigma $\mathrm{F}$ factor & प & 0.65 \\
\hline & KGT41714 & stage III sporulation protein $\mathrm{AH}$ & 0.72 & 0.64 \\
\hline & KGT41715 & stage III sporulation protein AG & 1.59 & 1.58 \\
\hline & KGT41946 & BofC protein & 0.66 & 0.54 \\
\hline & KGT41948 & spore cortex protein & 0.69 & प \\
\hline & KGT41949 & $\begin{array}{l}\text { peptigoglycan-binding protein } \\
\text { LysM }\end{array}$ & प & 0.57 \\
\hline & KGT41988 & spore coat protein CotS & 1.49 & [] \\
\hline & KGT42013 & $\begin{array}{l}\text { LuxR family transcriptional } \\
\text { regulator }\end{array}$ & 0.66 & 0.48 \\
\hline & KGT42151 & spore protein & 1.6 & प \\
\hline & KGT42445 & spore coat protein & 1.7 & प \\
\hline & KGT42520 & cell division protein FtsY & ए & 1.52 \\
\hline & KGT42664 & $\begin{array}{l}\text { small acid-soluble spore protein } \\
\text { Tlp }\end{array}$ & 0.72 & प \\
\hline & KGT42674 & spore protein $\mathrm{P}$ & 0.62 & ए \\
\hline & KGT44175 & transition state regulator Abh & 1.75 & 2.75 \\
\hline & KGT44210 & Spore coat protein $\mathrm{G}$ & 1.52 & प \\
\hline & KGT44211 & spore coat protein & 0.75 & 0.61 \\
\hline & KGT44517 & flagellar motor switch protein & 0.75 & प \\
\hline & KGT44707 & cell division protein GpsB & प & 2.01 \\
\hline & KGT44778 & spore coat protein & ए & 0.62 \\
\hline & KGT44827 & cell division protein FtsN & 1.49 & Q \\
\hline & KGT44878 & internalin & 0.58 & 0.61 \\
\hline & KGT45203 & spore protein & 2.01 & 2.23 \\
\hline & KGT45346 & stage V sporulation protein $\mathrm{R}$ & ए & 0.66 \\
\hline & KGT45552 & acid-soluble spore protein $\mathrm{H}$ & 0.7 & 0.5 \\
\hline & KGT45755 & spore protein & ए & 0.45 \\
\hline & KGT45877 & sporulation protein & 0.76 & 0.54 \\
\hline & KGT45955 & spore gernimation protein GerD & 0.64 & 0.47 \\
\hline & KGT45975 & protein sspF & 1.9 & 1.52 \\
\hline & KGT45993 & stage II sporulation protein $\mathrm{E}$ & 1.5 & प \\
\hline \multirow{2}{*}{$\begin{array}{c}\text { Energy } \\
\text { Metabolism }\end{array}$} & KGT41105 & ATP F0F1 synthase subunit B & 0.67 & 0.6 \\
\hline & KGT45463 & quinol oxidase subunit 2 & प & 1.57 \\
\hline
\end{tabular}




\begin{tabular}{|l|l|l|c|c|}
\hline Function & Accession & \multicolumn{1}{|c|}{ Protein description } & $\begin{array}{c}\text { Fold } \\
\text { Change } \\
(24 \mathrm{~h}: 12 \mathrm{~h})\end{array}$ & $\begin{array}{c}\text { Fold } \\
\text { Change } \\
\text { (48h:12h) }\end{array}$ \\
\hline \multirow{5}{*}{} & KGT44670 & $\begin{array}{l}\text { menaquinol-cytochrome C } \\
\text { reductase }\end{array}$ & 1.35 & 1.77 \\
\cline { 2 - 5 } & KGT42309 & $\begin{array}{l}\text { cytochrome D ubiquinol oxidase } \\
\text { subunit I }\end{array}$ & $\square$ & 2.33 \\
\cline { 2 - 5 } & KGT44113 & nitrate reductase & $\square$ & 2.47 \\
\cline { 2 - 5 } & KGT44114 & nitrate reductase & $\square$ & 1.92 \\
\cline { 2 - 5 } & KGT44115 & nitrate reductase & 1.92 & 2.75 \\
\cline { 2 - 5 } & KGT44130 & nitrite reductase & $\square$ & 2.65 \\
\cline { 2 - 5 } & KGT44131 & nitrite reductase & & \\
\hline
\end{tabular}

Accession: Protein accession from NCBI database; Protein description: Protein NCBI description; Fold change (24h:12h) and (48h:12h) were obtained from anti-log conversion of $\log _{2}$ ratios.

\section{Additional File Legends}

Additional file 1:

Table S1-1. Significantly changed proteins identified in pair of 24h:12h and 48h:12h.

Table S1-2. EMP, PP, TCA enzymes and their average abundance in three time-point samples.

Table S1-3. Enzymes in butanoate and pyruvate anaerobic metabolism and the abundance at three different time points.

Table S1-4. Significantly changed proteins related with stress and sporulation.

Table S1-5. Protein abundance of enzymes involved in oxidative phosphorylation and anaerobic/nitrate respiration.

Table S1-6. PHB biosynthesis and intracellular degradation enzymes and their average abundance in three time-point samples.

Additional file 2

Table S2-1. T-test and FDR analysis of $24 \mathrm{~h}-12 \mathrm{~h}$ pair of samples.

Table S2-2. T-test and FDR analysis of $48 \mathrm{~h}-12 \mathrm{~h}$ pair of samples.

Additional file 3

Table S3. Proteins identified and their normalized abundances in Bacillus cereus tsu1 in 12h-, 24h-, and 48h-culture. 


\section{Figures}

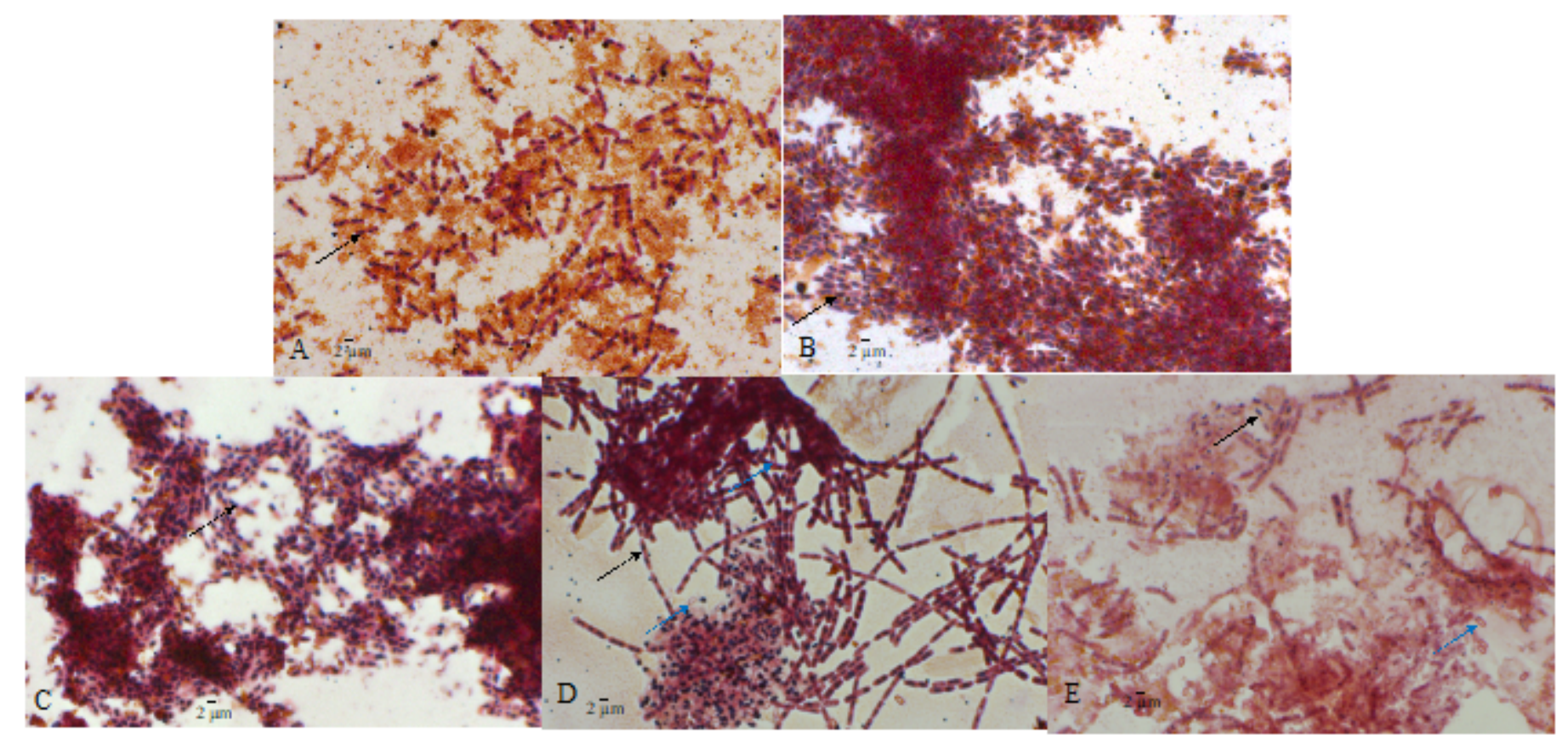

\section{Figure 1}

PHB accumulation status in B. cereus tsu1. B. cereus tsu1 was cultured in RCS medium for $6 \mathrm{~h}(\mathrm{~A}), 9 \mathrm{~h}$ (B) and $12 \mathrm{~h}(\mathrm{C}), 24 \mathrm{~h}(\mathrm{D}), 48 \mathrm{~h}(\mathrm{E})$. In RCS medium, PHB accumulation was observed at an early stage (6 h) and reached highest accumulation before $12 \mathrm{~h}$. Fore-spore and spore structure was observed at $24 \mathrm{~h}$, significant PHB degradation was observed at $48 \mathrm{~h}$. (Black arrow indicates PHB; blue arrow indicates forespore and spore). 


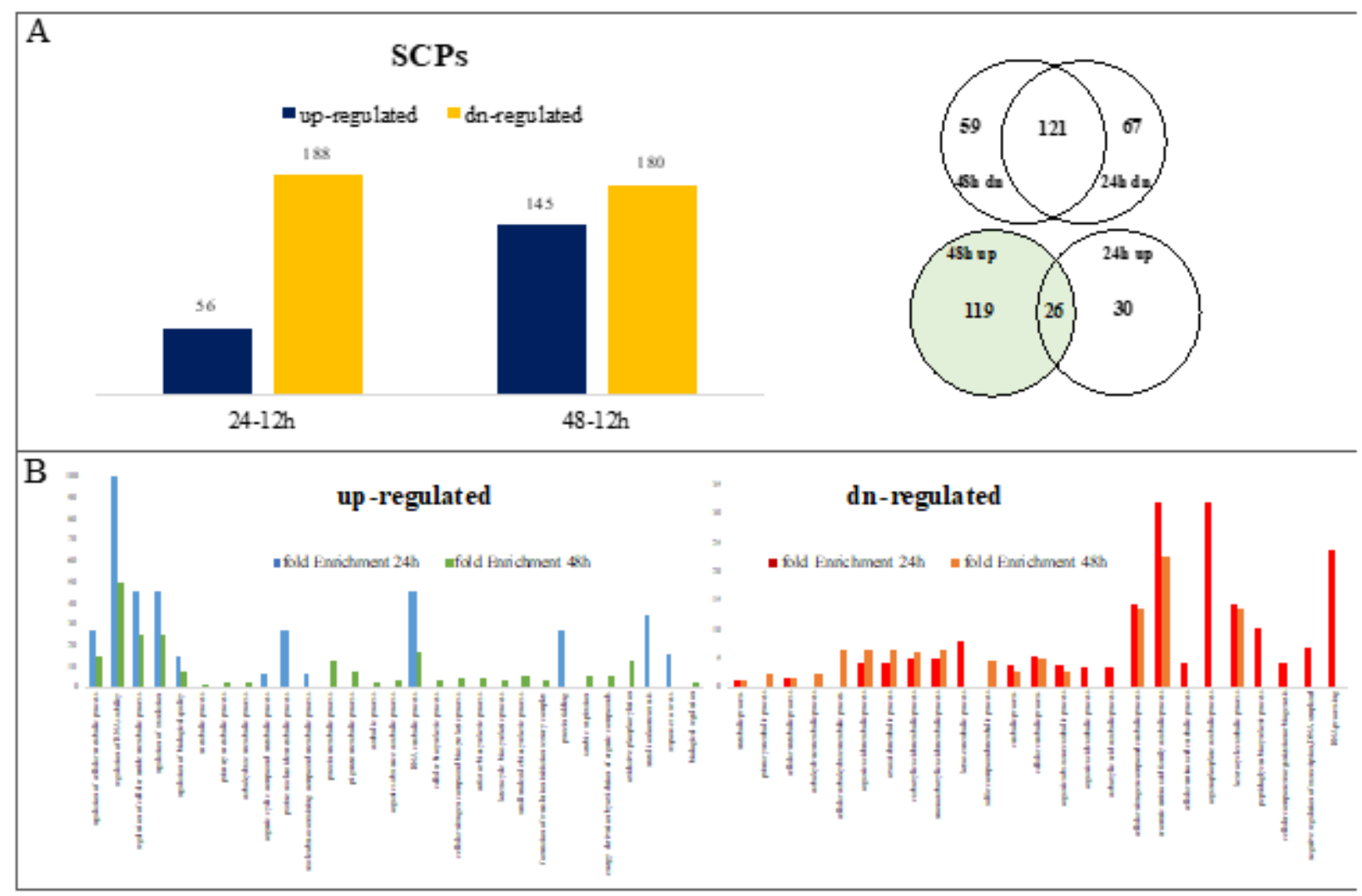

Figure 2

Significantly changed proteins (SCPS), and gene ontology classification using the PANTHER classification system. A: SCPs were compared between $24 \mathrm{~h}$ - and $12 \mathrm{~h}$-cultures (56 up-regulated proteins, 188 down-regulated protein), between $48 \mathrm{~h}$ - and 12h-cultures (145 up-regulated, 180 down-regulated); Venn diagram showing common and unique SCPs in $24 \mathrm{~h}-12 \mathrm{~h}$ and $48 \mathrm{~h}-12 \mathrm{~h}$ samples. B: Gene ontology classification. The enriched biological processes in 24 up-regulated SCPs (blue), 48 up-regulated SCPs (green), and 24 down-regulated SCPs (red), 48 down-regulated SCPs (orange) were compared. Proteins assigned to at least one category could be counted more than once. 


\begin{tabular}{|c|c|c|c|c|c|}
\hline Casavion & $\begin{array}{l}\text { protein } \\
\text { Sexcription }\end{array}$ & 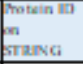 & $\begin{array}{l}\text { Ane. } 12 \mathrm{~h}-1 \\
\text { cample }\end{array}$ & $\begin{array}{l}\text { Aus. } 24 \text { h- } \\
\text { cample }\end{array}$ & $\begin{array}{l}\text { Ave. asto- } \\
\text { cample }\end{array}$ \\
\hline sctereass & 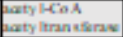 & $\min$ & 22243 & 258.7 & $2 \cos s$ \\
\hline Schral ssa & 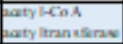 & $\sin$ & 13541.57 & $17 \operatorname{ess} 5$ & 10050.87 \\
\hline BCTranso 4 & 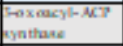 & hat & $1245 \times 5$ & 15759 & 17041.13 \\
\hline mitums 5 & 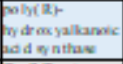 & $\tan$ & 15255350 & $95 \$ 20123$ & $\mathrm{ss} 5 \mathrm{s.93}$ \\
\hline ECTr4ass 1 & $\begin{array}{l}\text { ma? masen } \\
\text { potein }\end{array}$ & $\operatorname{man}$ & 2975.77 & $2695 x 3$ & 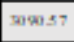 \\
\hline & fialpmotein & ตม & & 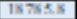 & 720 \\
\hline
\end{tabular}

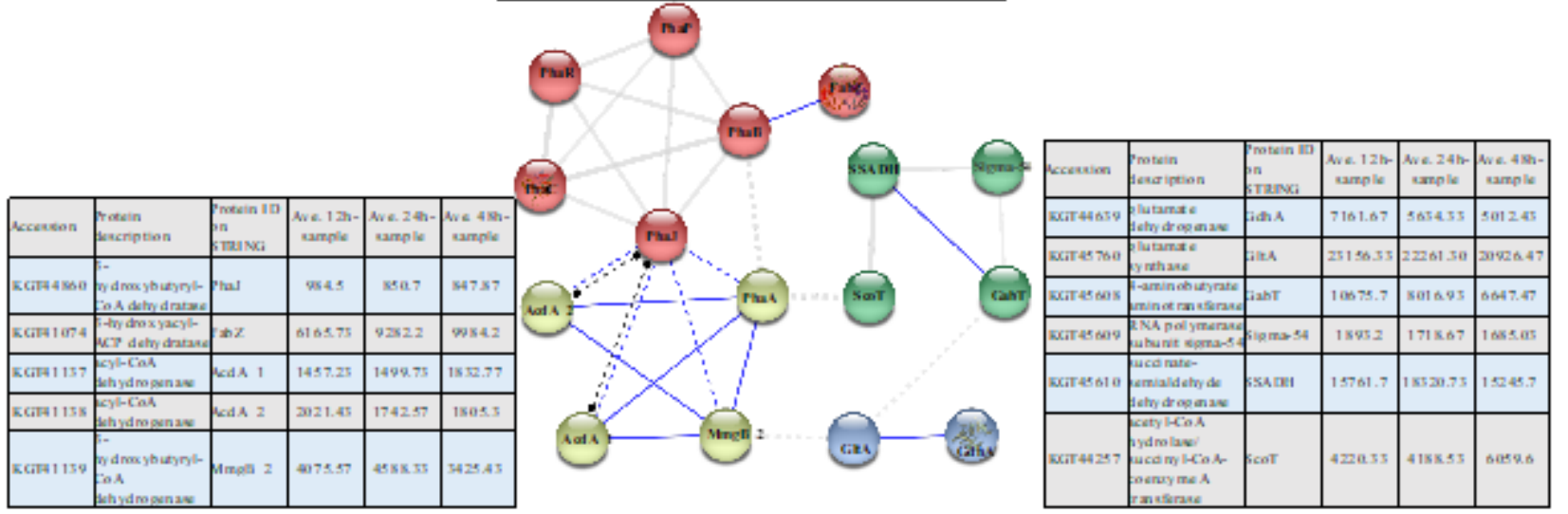

Figure 3

STRING protein interaction network of enzymes for PHB biosynthesis pathways, and protein abundance levels over time. STRING version 10.5 was used to construct protein-protein interaction networks of PHB biosynthesis enzymes in annotated genome of B cereus tsu1. Medium confidence ( 0.400$)$ was applied and disconnected nodes were hidden. MCL clustering was using inflation parameter 3 . Lines between nodes represent their action effects. (Red nodes represent proteins using acetyl-CoA; yellow nodes represent proteins using intermediates from fatty acid $\beta$-oxidation; green/blue nodes are proteins using glutamate and succinyl-CoA for PHB production.) Enzymes for PHB biosynthesis and their abundance level at three time points are listed in Additional file 1: Table S1-6.

A

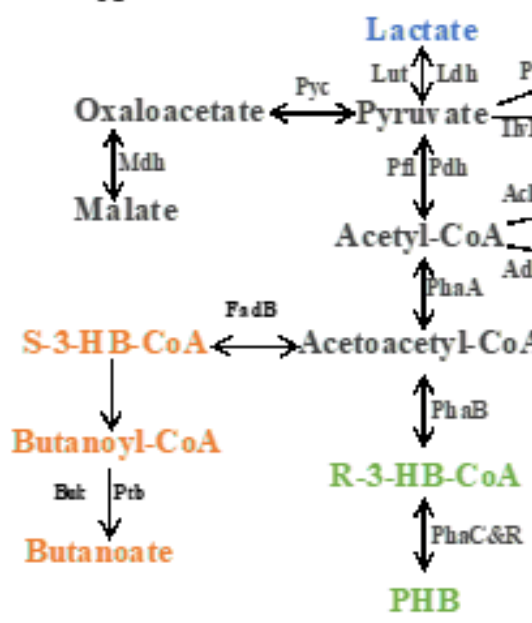

B

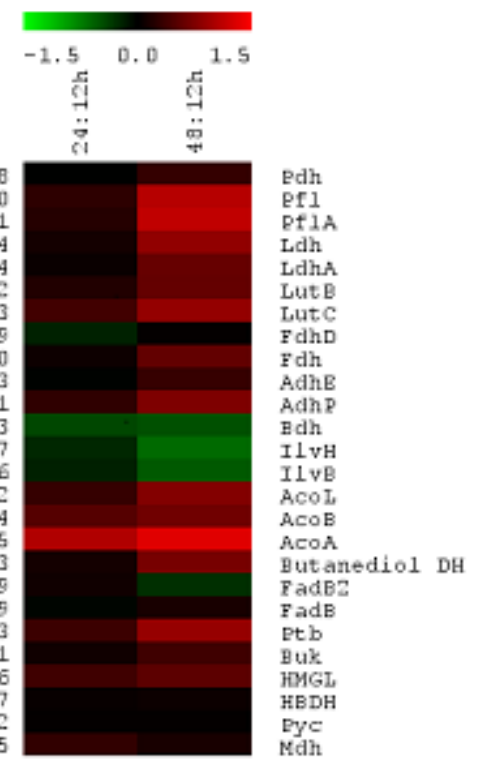




\section{Figure 4}

Schematics of pathways related with PHB intracellular mobilization. A: Interactions between PHB intracellular mobilization, and other major related pathways. Glycolysis, lipid and amino acid metabolism, and TCA are directly or indirectly provide carbon resource for PHB biosynthesis. Pyruvate (anaerobic) fermentation, butanoate metabolism compete the carbon resource with PHB synthesis. B: Heat map showing log2 transformed fold changes of proteins in pathways related with PHB intracellular mobilization.

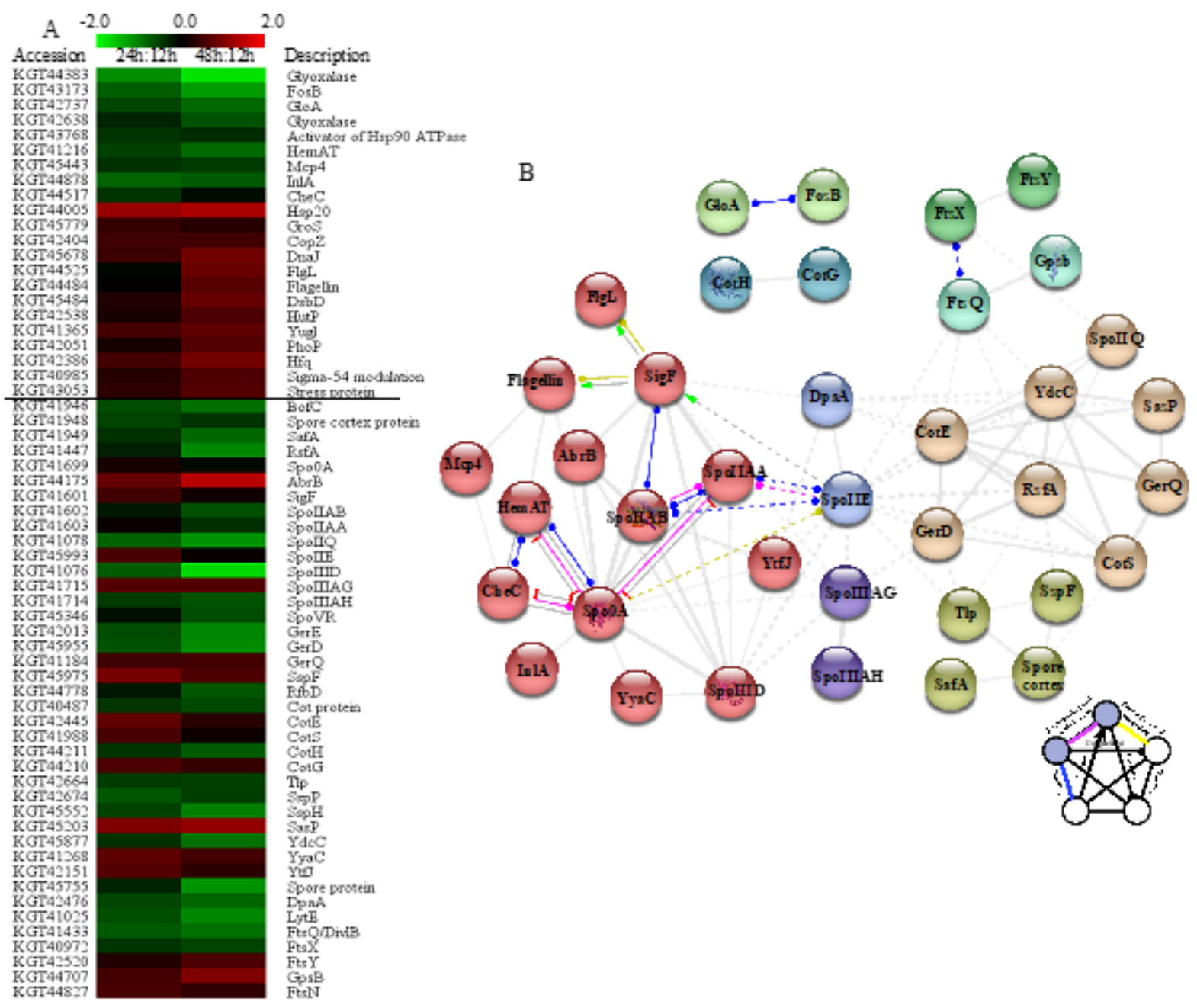

Figure 5

Sporulation-related and stress-induced proteins. A: Heat map showing log2 fold changes of proteins associated with stress and sporulation annotated on B. cereus tsu1. B: STRING version 10.5 was used to build protein-protein interaction networks of significantly changed sporulation and stress proteins. The lines in between two nodes indicate the predicted mode of actions. Red nodes represent proteins regulating sporulation process. Spoll $\mathrm{E}$ is an activator of sigF, which is a regulator of asymmetric division and flagella proteins. 

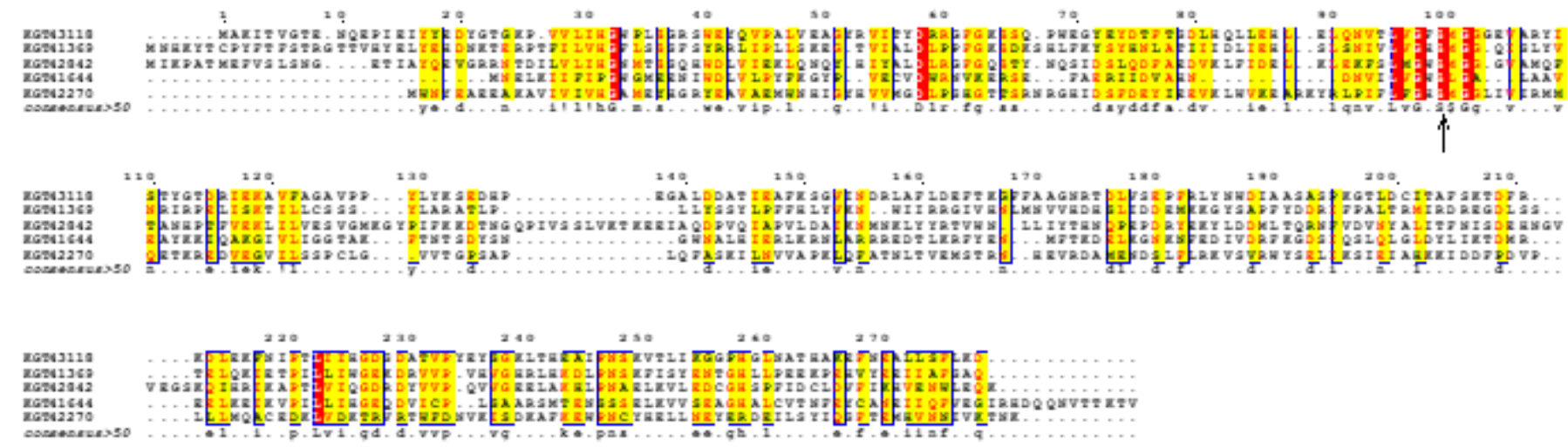

\section{Figure 6}

Multiple sequence alignment of $A / B$ hydrolase superfamily proteins on $B$ cereus tsu1 genome. Multiple sequence alignment of $A / B$ hydrolase proteins were performed using ClustalW followed by online-based ESPript 3.0. The consensus sequences between 3-oxoadipate enol-lactonase (KGT42842) and A/B hydrolase enzymes on B cereus tsu1 genome are highlighted in yellow and pink boxes. The lipase-box like sequence (GXSXG) and the serine site that are important for the PHB-hydrolyzing activity were detected on these A/B hydrolase proteins.

\section{Supplementary Files}

This is a list of supplementary files associated with this preprint. Click to download.

- AdditionalFile3.xlsx

- AdditionalFile1.xlsx

- AdditionalFile2.xlsx 